\title{
Validating the return period of rainfall thresholds used for Extreme Rainfall Alerts by linking rainfall intensities with observed surface water flood events
}

\author{
A.P. Hurford ${ }^{1}$, D.J. Parker ${ }^{2}$, S.J. Priest $^{2}$ and D.M. Lumbroso ${ }^{1}$ \\ ${ }^{1}$ HR Wallingford, Howbery Park, Wallingford, Oxfordshire, UK, OX10 8BA \\ 2 Flood Hazard Research Centre, Middlesex University, Trent Park, Bramley Road, London, UK, N14 4 YZ
}

Published in the Journal of Flood Risk Management: Volume 5, Issue 2, June 2012

\section{Abstract}

In 2008 the Environment Agency and the Meteorological Office launched a pilot Extreme Rainfall Alert (ERA) service as a first step towards providing a warning for surface water flooding (SWF). An ERA is based on rainfall-intensity thresholds of an average of 1-in-30 year storms, to represent rainfall thought likely to cause severe SWF in urban areas. This research investigates whether this return period is appropriate for warning of SWF by examining the intensity and return period of rainfall associated with observed surface water flood events. Data from rainfall gauges and flood events were analysed which showed that most of the SWF events were associated with rainfall intensities of less than 1-in-10 year return period. Improvements in data recording could provide flood magnitudes and durations, which would facilitate better understanding of the relationship between flood magnitude and rainfall intensity and allow more informed debate about SWF warning thresholds.

\section{Keywords}

extreme rainfall, surface water flooding, pluvial flooding, flood warning, rainfall intensity, depth-durationfrequency

\section{Introduction}

Apart from several small, highly localised rainfall-triggered and surface water flood warning systems, it is currently largely infeasible to provide surface water flood (SWF) warnings in England and Wales (Priest et al. 2010). However, much of the serious flooding of property during the summer 2007 floods is believed to have been caused by surface water flooding (Marsh and Hannaford 2007). Not surprisingly, therefore, the Pitt Review of 2008 (Pitt 2008) which investigated these floods concluded that flood warnings should be improved and extended to all sources of flooding including surface water flooding. A first attempt has been made in moving towards this type of warning in the implementation of the Extreme Rainfall Alert (ERA) service (Flood Forecasting Centre (FFC) 2010). This was developed (initially as a pilot) as a direct result of the Pitt Review and as a collaborative venture between the Meteorological Office (MO) and the Environment Agency (EA) (the flood risk management agency for England and Wales) - greater cooperation between these two bodies in providing flood warnings being one of the recommendations of the review (Pitt 2008). For the purposes of this study, 
surface water flooding and pluvial flooding were taken to be synonymous. The meaning was rainfall generated flooding which results from relatively short periods of high intensity rainfall leading to flooding of areas before the rainwater is able to enter natural or engineered drainage systems.

The ERA service is based on the exceedance of national rainfall thresholds deemed likely to cause severe surface water flooding in urban areas. The thresholds were developed in a scoping study (Halcrow 2008) by averaging 1-in-30 year return period Flood Estimation Handbook (FEH) (Institute of Hydrology 1999) rainfall intensities for eight UK cities at 1-, 3- and 6-hour storm durations. The 30-year return period was selected as the design standard for most urban drainage systems (WRc 2006) and exceedance of which is likely to lead to these systems being overwhelmed. It was noted that although this is the design standard, variation in construction standards, overland flow paths and drainage system entry mean that the flooding will often occur at much lower return periods of rainfall intensity (Halcrow 2008). The ERA service is part of the rainfall-based alert services offered by the UK MO which includes the National Severe Weather Warning Service (NSWWS). The NSWSS provides Advisories, Early Warnings and Flash Warnings directly to professional emergency responders through the $\mathrm{MO}$ website and through the media to the public about weather including heavy rainfall. Advisories are issued daily and provide information on weather events up to five days ahead, indicating the probability of occurrence (as a percentage) of the expected weather. Warnings are issued at county or unitary authority level (Flood Forecasting Centre 2010).

The present research aims to investigate whether analysis of the rainfall intensities associated with observed surface water flood events provides an indication of the validity of the current ERA thresholds nationally, regionally and comparing urban and rural areas.

Three case study areas were identified in order to limit the scope of the work, which formed one technical component of a wider ranging project funded by the EA to scope the options for development of a surface water flood warning service (Priest et al. 2010 Priest et al., in press). The data used in this study related to the duration of the ERA pilot service, which ran from $1^{\text {st }}$ July 2008 to $29^{\text {th }}$ February 2009 . The ERA service has since undergone significant developments and become a live service.

\section{Examples of other SWF warnings}

Genuine SWF warning systems are currently rare. The US Flash Flood Guidance System (FFGS) provides "the near-term risk of a flash flood in small streams and basins" (Stewart 2007) and has been developed by the Hydrologic Research Center (HRC) in San Diego, California. Flash flooding is rapid onset flooding which usually occurs on rivers, without warning, in catchments which respond extremely rapidly to intense rainfall events. The aim of the US FFGS is to provide a diagnostic value (known as flash flood guidance) that estimates the amount of rainfall over a given duration within a basin that is required in order to cause flooding within the catchment. The system has been used for many years by the US National Weather Service (Carpenter et al. 1999) but focuses mainly upon flash floods of which surface water flooding might, under given circumstances be part, but no specific SWF warning service is advertised or provided. More recently this has been extended to Central America (see http://www.hrc-lab.org/right nav widgets/realtime caffg/index.php).

The European Meteoalarm system provides a heavy rainfall alert service but this generally provides unspecific warnings of local flooding (www.meteoalarm.eu). France provides a publicly available on-line service called France Vigilance Météorologique which provides warnings and guidance for meteorological hazards including high precipitation/floods (http://france.meteofrance.com/vigilance/Accueil). The system provides a simple summary of information focussing on dangerous phenomena, emphasising the need to stay informed (Carriére 2006). The service is viewed as a step forward as it translated the intensity of the meteorological phenomena 
parameters into a risk level. Forecasts are provided on maps for the next 24 hours of meteorological conditions that may prove to be hazardous with four different risk levels based on a traffic-light system of increasing severity. These maps are updated twice daily (at $6 \mathrm{am}$ and $4 \mathrm{pm}$ ), although at times of alert they may be updated more frequently and, in particular, the bulletin with specific instructions and guidance is updated every three hours. The national map provides an overview by department which, via the website, links to a local scale map and, if appropriate, to localised warnings. However, the warning is based on rainfall thresholds rather than on any specific procedure to determine whether surface water or pluvial flooding is likely.

The rainfall and flood alert system operated for the City of Marseilles, France appears to be close to a genuine SWF warning service because it links rainfall intensities to locally relevant flooding thresholds for floods of different estimated return periods (Deshons 2002). Four levels of alert have been defined, according to rainfall intensity ( $\mathrm{mm} /$ hour) and rainfall accumulation $(\mathrm{mm})$. To each a return period and likely consequences (e.g. overland flow sufficiently strong to overturn vehicles) have been assigned and together with expected municipal interventions.

Golding (2009) describes an example of where an Extreme Rainfall Alert issued in pilot mode has been used operationally when leading to both surface water and fluvial flooding in Northern Ireland in August 2008. He suggests that more emphasis should be given to coupling rainfall-runoff models with high resolution Numerical Weather Prediction models.

What all these warning systems lack, but which the Marseilles system perhaps comes closest to achieving, is effective coupling of weather and rainfall prediction models and rainfall-runoff models which allow flood impact, in terms of flooding location and extent, to be predicted. The potential for this coupling is being investigated for the UK, and the Pluvial Extreme Event Planning system (PEEPs) has been developed with a view to providing such a coupling with the ERA service in future (Falconer 2009, Falconer et al. 2009). Currently however, in the absence of such well developed coupled rainfall/SWF prediction models, but in the presence of a functioning ERA service in England and Wales, this paper seeks to explore the relationship between ERAs on the one hand, and observed SWF events on the other. This represents an exploration in the eventual development of coupled hydrometeorological models which in future are able to provide sufficiently accurate and reliable SWF forecasts on which to base locally-specific SWF warnings.

Research conducted as part of the EU-funded FLOODsite project investigated the effectiveness of a Flash Flood Guidance (FFG) approach in Europe and evaluated a threshold-based flood warning approach for flash flooding in watercourses and drainage systems (Borga et al. 2008). Through an analysis of system performances and data on operational quality for eleven European basins Borga et al $(2009 ; 4)$ highlighted that the difference between a FFG approach and a direct model application were "modest, and decrease with decreasing accuracy of the model application." In particular, they emphasise the importance of estimating and including soil moisture conditions for improving the results of the FFG approach. Although of interest, the use of soil moisture information may have less relevance in the context of estimating SWF in urban areas. Despite this study being primarily concerned with a warning approach for flash flooding, some lessons about the data requirements and the scaling of information are clearly applicable for investigating the provision of a warning for surface water flooding. 


\section{Methodology}

\section{Case study area selection}

Case study areas were selected on the basis of the prevalence of ERA events relating to them during the pilot period of the service (a forecast extreme rainfall 'event' might have more than one alert issued in relation to it, as the probability of occurrence changes or as the predicted intensity or location changes). The three areas to which most ERA events related were Cumbria, southern Wales and the south-west of England. In addition, many of the same weather systems affect the latter two areas, meaning that the location of an intense event cannot sometimes be predicted on a smaller scale than across both. This made it impractical to choose one of these areas for a case study but not the other.

\section{Data availability, collection and analysis}

Contact was made with relevant regional EA offices to enquire about the availability of rainfall and flood event data and to utilise existing contacts between the EA and professional emergency responders or Category 1 (e.g. local authorities, 'blue light' emergency services) and 2 responders (e.g. utility and transportation companies) who might gather these data. Category 1 and 2 responders are those organisations that have responsibilities to respond to flooding under the Civil Contingencies Act 2004 (HM Government 2004).

\section{Rainfall data}

Rainfall gauge data were requested for EA gauges in all three areas, and it was possible to obtain records for the whole study period from 333 gauges (see Figure 1). Radar data are able to provide a better representation of spatial variations in rainfall and therefore indications of the intensities which actually fell in the small spatial area of only a few kilometres often covered by intense convective type storm cells (Goudenhoofdt et al. 2010). They were not used in this particular research project because of the time-consuming and costly nature of the analysis required.

Raingauge data were available either as 15 minute totals or as precisely timed bucket tips representing $0.2 \mathrm{~mm}$ of rainfall each. While the latter required more complex processing, it was possible to use all these data to find peaks in the recording rainfall intensities. 


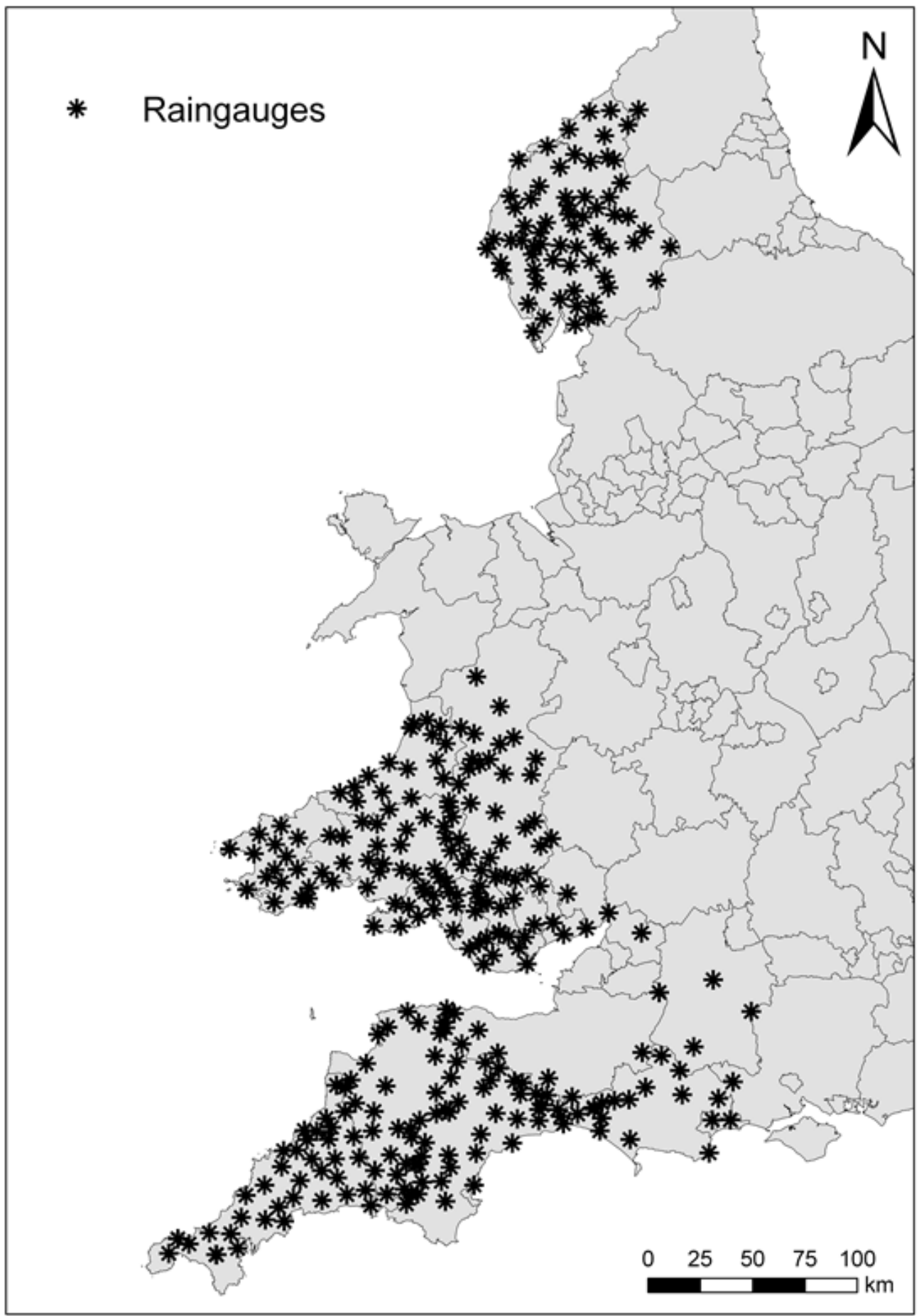

Figure 1: Locations of the 333 EA rain gauges for which data were made available

The day of rainfall data (midnight to midnight) for the nearest rain gauge to each SWF (see below) event was interrogated to find the maximum one, three and six hour rainfall intensity falling during this period. These durations of rainfall were chosen as corresponding to, and facilitating comparison with, the current ERA thresholds: $30 \mathrm{~mm}$ in one hour, $40 \mathrm{~mm}$ in three hours, and $50 \mathrm{~mm}$ in six hours. The requirement for a peak six 
hour intensity could cause a problem where the peak intensity occurred within the first 6 hours of the date on which the flood was reported, but this was avoided by extending the analysis back to the start of the storm where it began on the previous day.

\section{Flood event data}

It was possible to obtain 1393 reports of flooding from all sources during the study period. These data were analysed to filter those likely to have been surface water events from those which are more likely to have originated from another source. This analysis utilises the information available in relation to each event, which was variable, but always included at least a location (the majority with grid reference, otherwise with place name). The best quality data are available from the fire and rescue service, as these usually include time of call out. The problem with these data is that log reports relating to flooding can include events such as burst pipes or leaking washing machines for which the service is sometimes called out.

\section{Identifying surface water flood events}

The data obtained are of a limited quality for this kind of study, in terms of their consistency and their lack of detail regarding flood timings and magnitude, but are nonetheless currently the best available. These facts dictate that sophisticated analysis for filtering is not practical although best use is made of the available data for a high-level assessment.

The primary analysis was carried out by plotting the flood location data in a GIS and assessing the likelihood of the source being surface water. The main criterion for assessment is the proximity of the event location to a watercourse of some kind (being close to a watercourse suggesting a fluvial flood event), as shown on 1:10 000 scale Ordnance Survey mapping. The following other factors, based on broad assumptions, are all taken into account as no further information is available:

- proximity to the coastline would suggest the possibility of coastal flooding so such events are ruled out as surface water flooding (SWF);

- incident angle of watercourses/drainage channels approaching the location - where the flood location is on the outside bend of a small watercourse this would suggest more likely a fluvial event;

- 'sinking' and 'issuing' marked on map relating to watercourses on either side of a location - flooding was considered to be more likely upstream (i.e. in the vicinity of 'sinking') due to overloading of a point where water enters a hydraulic flow control (such as a culvert). Issuing is where a watercourse emerges from a feature such as a culvert and this was considered unlikely to be point vulnerable to flooding due to the limit of flow through the culvert (for example) - the presence of either of these was taken as an indicator that the event was not SWF as defined by the EA for the purposes of this study (Priest et al. 2010)

- mention of blocked drains in the incident description - this is considered surface water flooding as there is no way to discriminate between blocked drains and surcharging drains even where mentioned. Water company DG5 records could be used in future studies to investigate this further; and

- mention of 'out of bank flows' or rain causing a river to increase flow - this is not considered as SWF.

There are no doubt occasions where an event which could have been SWF was excluded on the basis of the above factors, but this is considered a conservative approach and better than including events in the subsequent analysis which are unlikely to be SWF. Inclusion of events unlikely to be SWF and therefore unrelated to the ERAs would misrepresent the return periods of rainfall which can be associated with SWF. 


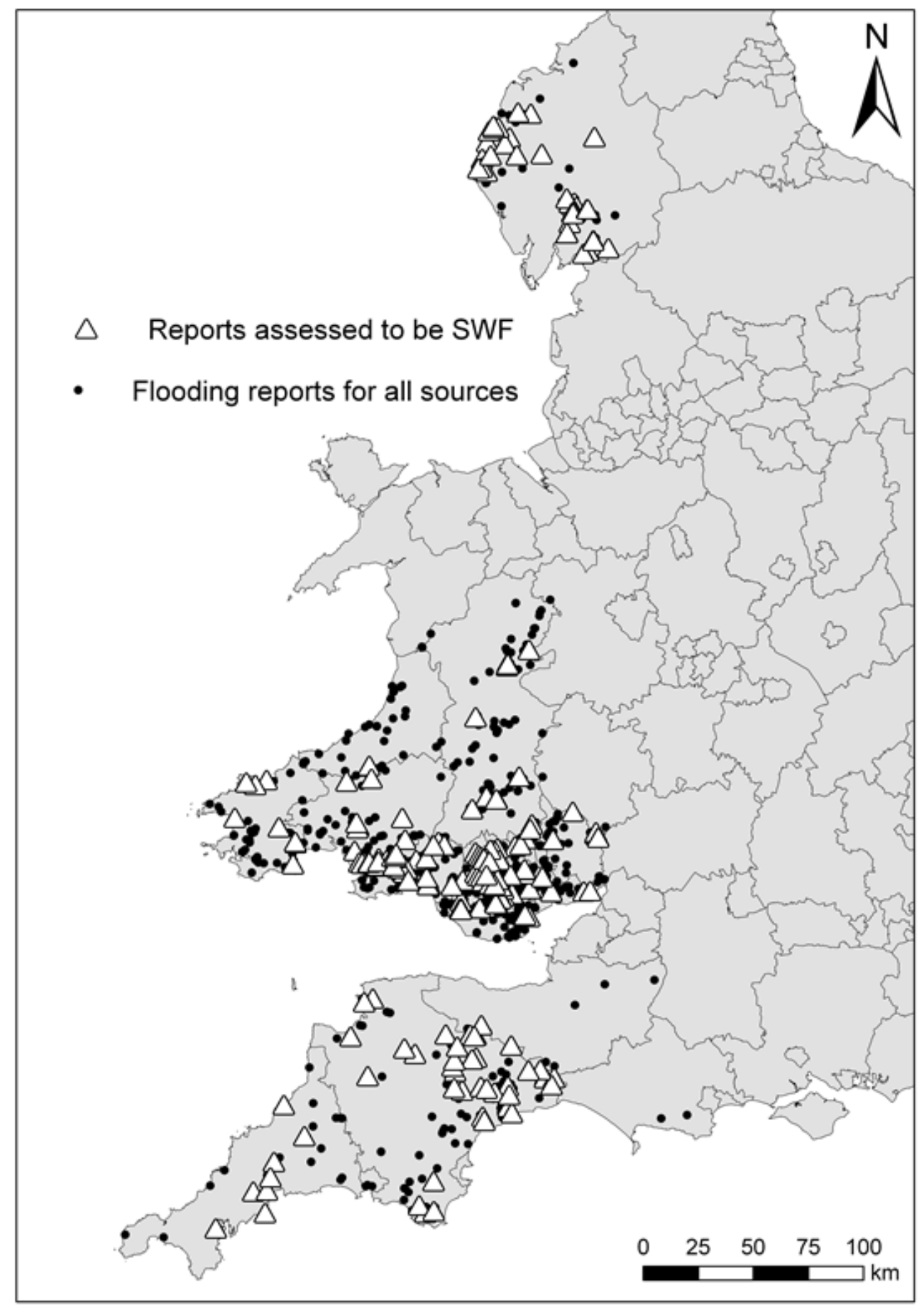

Figure 2: Location of all flood events with different symbols denoting those events assumed to be SWF or flooding from other sources

A second round of manual filtering utilised flood report timing (where available) in conjunction with peak one hour rainfall intensity timing resulting from the analysis described above. Those floods which were reported close to the peak intensity (within 3-4 hours) were thereby separated from those occurring over longer time periods. This window could be considered wide for a SWF response to occur from a rainfall event, but owing to 
the distances between flood locations and rain gauges (see below) and less likely rapid responses in many areas due to them being relatively rural, it was considered appropriate for this analysis.

By the methods described above, the intial total of 1393 flood reports were reduced to 286 surface water flood events for further analysis, representing $20.5 \%$ of the original dataset. The full dataset is shown in Figure 2, with different symbols representing the SWF events and flooding from other sources.

\section{Spatial relationship between flooding and rainfall gauging}

For this study, analyses were limited to the use of rainfall gauging stations rather than radar as described above. A consequence of this was the need to assume that the rainfall recorded at the nearest gauge was the same as at the site where flooding was reported. Some allowances were made for this assumption, such as in the timing between when intense rainfall was recorded and when flooding occurred, as described in the previous section above. As an indicator of the distances being considered, Table 1 shows some statistics by region, relating to the proximity of the nearest raingauges to the events identified as SWF. These statistics should be considered in light of the fact that intense rainfall events often result from convective cloud processes which can be confined over distances as small as $1-2 \mathrm{~km}$.

Table 1: Summary statistics of nearest rain gauge proximity to SWF events in kilometres

\begin{tabular}{|l|r|r|r|r|}
\hline & Cumbria & Wales & South-west & Combined \\
\hline Number of events* & 44 & 168 & 57 & 269 \\
\hline Minimum distance $(\mathrm{km})$ & 0.4 & 0.5 & 0.6 & 0.4 \\
\hline Maximum distance $(\mathrm{km})$ & 9.1 & 19.5 & 16.5 & 19.5 \\
\hline Mean distance $(\mathrm{km})$ & 4.0 & 4.9 & 5.2 & 4.8 \\
\hline Median distance $(\mathrm{km})$ & 3.9 & 4.1 & 4.4 & 4.2 \\
\hline
\end{tabular}

* number of events only includes those for which related rainfall data were available

\section{Rainfall return period analysis}

As the current ERA thresholds were devised on the basis of a 30-year return period storm intensity, it was logical for comparison to assess the return periods of the storms associated with the flood events reported in the data available for this study.

Rather than assessing the accurate return period of each duration event (1, 3, 6 hours) for each rain gauge location relating to a SWF event, it was considered more appropriate to represent the data graphically to give an idea of the range of return period storms occurring.

\section{Regionalising rainfall gauges}

As this research was conducted on a restricted timescale, it was considered reasonable to regionalise the rainfall gauges to avoid a lengthy process of analysing each of the gauges related to a flood event.

For each case study area, relevant rain gauges (those nearest to one or more SWF events) were ranked on the basis of the 100-year return period, 1, 3 and 6 hour storm depths at their location. The median of each ranking was calculated and used to split the group into two - a Lower Rainfall Area and a Higher Rainfall Area, below and above the median respectively. Each Area was then represented by the rain gauge with its own median 100 
year rainfall depth, or the two gauges either side of the median value for the group where it contained an even number of gauges.

\section{Defining regional DDF curves}

Rainfall Depth-Duration-Frequency (DDF) curves were exported from the Flood Estimation Handbook (FEH) (Institute of Hydrology 1999) data for the point grid reference location of each of these representative gauges. Where two gauges represented an Area, each value in the Area's DDF table was created by averaging corresponding DDF values from the two point locations of these gauges. This process produced representative High and Low rainfall DDF curves for each case study area and each rainfall duration (as the initial ranking of rain gauges varied according to storm duration).

\section{Comparing observed rainfall to DDF curves}

Observed rainfall depths associated with SWF events were then plotted against the representative DDF curves for their area to demonstrate the range of return period rainfall events associated with surface water flooding. It is assumed for the purposes of this analysis that the rainfall occurring at the nearest rain gauge is representative of that which caused the flooding.

\section{Assessing differences in rainfall between urban and rural SWF}

The case study areas chosen for this work are predominantly rural, with pockets of urban development, but that description could be applied to the UK as a whole (Office of National Statistics 2005). The ERA system was intended to provide warnings for urban areas in particular, as these are where the majority of the population (and therefore potential victims of flooding) reside. It is also where urban drainage systems are likely to be installed to deal with storm water, preventing SWF events at lower return periods. It was therefore reasonable to examine the data available to this study to consider whether there might be any difference in the rainfall depths associated with flooding in the urban areas compared to those in the rural areas.

Using a GIS layer of UK urban and rural extent, each flood event was classified as having occurred in either an urban or rural environment. Then, assuming that the rainfall which occurred at the nearest gauge was that which caused the flooding, a statistical analysis was conducted to determine whether the two sets of rainfall for urban and rural cases intensities (at durations of 1, 3 and 6 hours) were significantly different. This exercise was carried out for each of the case study areas individually as well as for the whole dataset combined.

\section{Results and discussion}

Figure 3 shows typical observed rainfall event depths associated with a reported SWF event in the context of the standard DDF curves for the case study area. The rainfall event depths and DDF curves are divided into those from the Low Rainfall Area and High Rainfall Area as described above. DDF curves for the 10-year, 50year and 100-year return period rainfall intensities are plotted and where the depth-duration plot associated with a SWF event is below the curve plotted by one of these return periods, this signifies that the return period of the SWF rainfall was lower.

Similar figures for all case study areas and rainfall durations clearly demonstrate that the vast majority of rainfall events associated with those SWF events represented by the data available for this analysis, are of less than 10 -year return period. This raises questions regarding the use of 30 -year return period depths as the thresholds 
for warning of SWF. These questions are strongly linked however, to questions about the size of event for which it is appropriate or even economically and technically viable to provide a warning. No data were available for this study to link rainfall intensities with impacts in terms of the relative damage caused by the associated flooding.

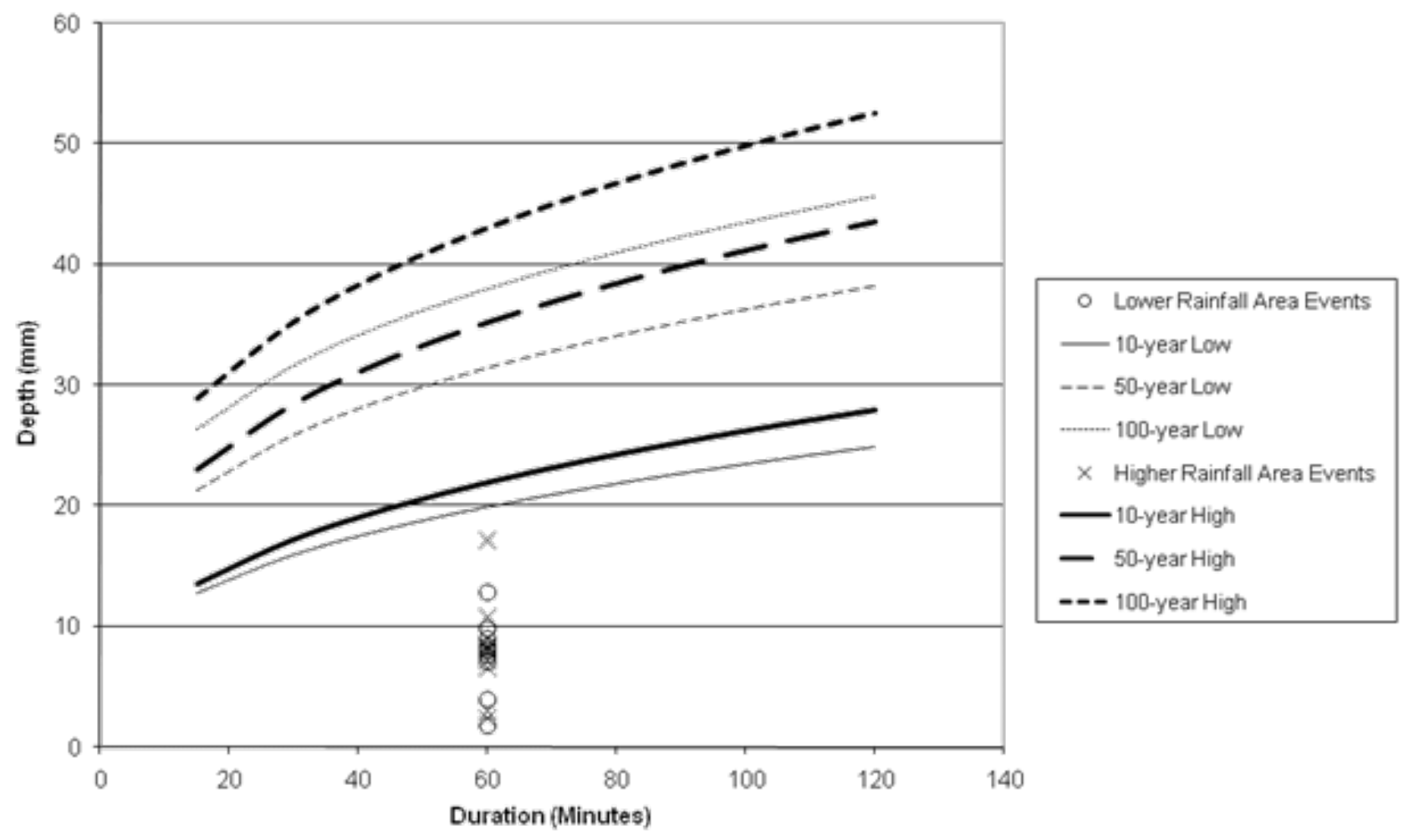

Figure 3: Typical example of localised DDF Curves, in this case for peak 1-hour rainfall associated with SWF events

\section{Comparing urban and rural SWF}

This analysis only highlighted statistically significant differences between urban and rural rainfall in Cumbria for 3-hour and 6-hour duration storms, and for the whole dataset for 1-hour storm duration. Table 2 shows the outputs of Student's t-tests comparing datasets of rainfall associated with urban and rural SWF events. It must be noted that the same data from various rain gauges are used in calculations from both the urban and rural dataset, which must account for a certain degree of similarity between them.

Table 2: Probabilities of a difference between the means of rainfall datasets (associated with urban/rural SWF events) occurring by chance

\begin{tabular}{|l|r|r|r|r|}
\hline$P(T<|t|)$ two-tail & Cumbria & Wales & South-west & All \\
\hline 1 Hour & 0.118 & 0.178 & 0.331 & $\underline{\mathbf{0 . 0 1 9}}$ \\
\hline 3 Hour & $\underline{\mathbf{0 . 0 0 2}}$ & 0.944 & 0.526 & 0.723 \\
\hline 6 Hour & $\underline{\mathbf{0 . 0 0 1}}$ & 0.942 & 0.375 & 0.120 \\
\hline
\end{tabular}

Note: Bold and underlined highlights significant differences between urban/rural rainfall datasets 
Overall this analysis of the available data does not provide strong evidence that there is a fundamental difference between urban and rural areas in the intensity of rainfall causing SWF events. An issue with the approach taken in this work is that it is unable to define a threshold rainfall intensity which must be exceeded in order to cause surface water flooding in a particular place, regardless of its urbanised extent. It has only been possible to associate rainfall intensities with observed SWF events, but not to say whether the SWF events would have also occurred at lower rainfall intensities.

The intensity of rainfall required to cause surface water flooding in urban areas is often different from the intensity required in rural areas due to reducing infiltration capacity as urbanisation intensifies. It is likely that analysis of more extensive data and of better quality would produce results highlighting differences between urban and rural areas in terms of SWF event frequency, duration and damage caused. A different methodology would be required to assess the difference from this perspective however.

\section{Conclusions}

The research carried out has demonstrated that SWF appears to occur at lower rainfall intensities and return periods than those used as thresholds in the ERA service. However, significant questions remain regarding the magnitude and duration of SWF represented by the flood event data which were available. These questions are vital to any development or updating of thresholds based on a similar approach. This in turn highlights the need to introduce a national standard for recording of flood event data, which would facilitate a more accurate analysis based on the methodology described in this paper. Without improved data it will not be possible to make effective decisions regarding how best to warn of potential SWF events.

The implications for the ERA service are that it is unlikely to provide warnings for all SWF events, and that further investigation should be undertaken to define more clearly the intensities of rainfall likely to result in the 'severe surface water flooding in urban areas' for which it is intended to warn. Existing radar data and future improvements in its accuracy could help to provide this. More consideration may also be necessary of what constitutes severe SWF and whether that definition is appropriate in terms of the damage which may be caused by less severe flooding and the cost:benefits of providing a warning for these events.

Improving the ERA service to successfully predict a greater proportion of SWF events above a minimum level of severity, and improving the recording of flood event data as suggested above, are steps which will be valuable in developing a fully-functioning SWF warning service for England and Wales. Such as service must also generate reasonably reliable and accurate locally-specific SWF flood forecasts and warnings. Improving the ERA service in these ways is likely to be welcomed by users, particularly professional emergency responders (Priest et al. 2010). Identifying locally relevant rainfall and runoff thresholds for surface water flooding, to complement and in some cases replace nationally defined rainfall thresholds, remains an important step to be undertaken in future as is the successful coupling of weather and rainfall-runoff models which posses the potential to predict locally-specific surface water flooding on which to base SWF warnings.

\section{Acknowledgements}

The research was a Science Project (SC080034) sponsored by the Environment Agency. The authors are grateful to staff from the Environment Agency and Fire and Rescue services who provided their data for this research; and to members of the project board - Katharine Evans, Jim Walker, Mel Andrews, Faye Burrows, Tony Deakin, Andy Fraser, Joanne Grimshaw, Chris Strong and Claire Sunshine. 


\section{References}

Borga, M. Gaume, E., Martina, M., Thielen, J. (2008) Real Time guidance for flash flood risk management, FLOODsite report, T16-08-02 Ed. 2 [online]

http://www.floodsite.net/html/partner area/project docs/T16 0802 Guidance FF Risk D16 1 V2 0 P01.pdf [Accessed 12 August 2011]

Carpenter, T., Sperfslage, J., Georgakakos, K., Sweeney, T., Fread, D. (1999) National threshold runoff estimation utilizing GIS in support of operational flash flood warning systems. J. Hydrol., 224, 21-44

Deshons, P. (2002) Prevision et suivi des crues urbaines. Experience de la ville de Marseille. La Houilles Blancin, No. 2, 56-59.

Falconer, R. (2009) Pluvial Flooding and Surface Water Management, 5th EWA Brussels Conference, 6th November 2009, European Water Management and Implementation of the Floods Directive.

Falconer, R.H., Cobby, D., Smyth, P., Astle, G., Dent, J. and Golding, B. (2009) Pluvial fooding: new approaches in flood warning, mapping and risk management, J Flood Risk Management, 2, (2009) 198-208

Flood Forecasting Centre (FFC) (2010) Extreme Rainfall Alert (ERA) Service User Guide [online] http://www.ffcenvironment-agency.metoffice.gov.uk/media/pdf/FFC ERA User Guide.pdf [accessed 23/08/10]

Golding, B. W. (2009) Long lead time flood warnings: reality or fantasy? Meteorol. Appl., 16, 3 -12.

Goudenhoofdt, E., Reyniers, M. and Delobbe, L. (2010) Long term analysis of convective storm tracks based on C-band radar reflectivity measurements. ERAD 2010 - The sixth European conference on radar in meteorology and hydrology [online] http://www.erad2010.org/pdf/oral/friday/nowcasting/03 ERAD2010 0122.pdf [accessed 04/03/2011].

Halcrow (2008) Proposed Pluvial Flooding Trial Service, Report prepared for the Meteorological Office. April 2008.

HM Government, 2004. Civil Contingencies Act, 2004. 2004c.36 [online]. http://www.opsi.gov.uk/acts/acts2004/ukpga_20040036_en_1 [Accessed 07/12/09].

Institute of Hydrology (1999) Flood Estimation Handbook, Institute of Hydrology, Wallingford, UK.

Marsh, T.J. and Hannaford, J. (2007) The summer 2007 floods in England and Wales - a hydrological appraisal. Centre for Ecology and Hydrology. 32pp.

Office for National Statistics (2005) Focus on People and Migration, Chapter 3: The UK's major urban areas [online]. http://www.statistics.gov.uk/statbase/product.asp?vlnk=12899 [accessed 04/03/11].

Pitt, M. (2008) Learning Lessons from the 2007 Floods. The Pitt Review, Cabinet Office, London.

Priest, S.J., Parker, D.J., Hurford, A.P., Pardoe, J.L., McCarthy, SS., Tapsell, S.M., (2010) Surface Water Flood Warning Scoping Project - Final Report, Environment Agency Science Programme Report, Science Report, SC080034/SR1.

Priest, S.J., Parker, D.P., Hurford, A.P., Walker, J. and Evans, K., (in press) Developing and assessing options for surface water flood warning in England and Wales, Journal of Environmental Management, DOI: DOI: 10.1002/joc2391. 
Stewart, B. (2007) Implementation of a flash flood guidance system with global coverage, A joint proposal by WMO Commission for Hydrology and WMO Commission for Basic Systems, April 2007, [online]. http://www.hrclab.org/giving/givingpdfs/WMOProspectus April-2007.pdf. [accessed 05/03/11).

WRc. (2006) Sewers for adoption,-- design and construction guide for developers, $6^{\text {th }}$ Edition, WRC, Swindon, UK. 